\title{
Ação e criação na interface das artes e da saúde*
}

\author{
Action and creation at the arts \\ and healthcare interface
}

\author{
Elizabeth M. F. Araújo Lima ${ }^{1}$, Erika Alvarez Inforsato ${ }^{2}$, \\ Leonardo José Costa de Lima ${ }^{3}$, Eliane Dias de Castro ${ }^{4}$
}

\begin{abstract}
LIMA, E. M. A.; INFORSATO, E. A.; LIMA, L. J. C. de; CASTRO, E. D. de. Ação e criação na interface das artes e da saúde. Rev. Ter. Ocup. Univ. São Paulo, v. 20, n. 3, p. 143-148, set./dez. 2009.

RESUMO: Este artigo apresenta a experiência de constituição e implantação do Laboratório de Estudos e Pesquisa Arte e Corpo em Terapia Ocupacional e do Programa Permanente Composições Artísticas e Terapia Ocupacional na Universidade de São Paulo, Brasil. Propõe-se a traçar um panorama das atividades de ensino, pesquisa e extensão à comunidade que configuram um novo campo de práticas de terapia ocupacional voltadas às complexas demandas da população atendida nesta área e à ampliação de sua participação sociocultural. Tem realizado pesquisas qualitativas através da metodologia da pesquisa-ação para a construção de um conhecimento local em terapia ocupacional orientado pela importância das ações criativas e por referenciais clínicos e artísticoculturais. As ações desenvolvidas ampliaram o acesso da população atendida às atividades artísticas e às experiências culturais, constituindo-se em estratégias de construção de projetos de vida, de formas de participação, de convivência e de trocas subjetivas, configurando modos inusitados de produção de valor social.
\end{abstract}

DESCRITORES: Terapia ocupacional/tendências. Terapia pela arte/tendências. Projetos de investimento social.

\footnotetext{
* Este artigo é desdobramento do Projeto FAPESP 02/10358-3 e teve aprovação da Comissão de Ética para Análise de Projetos de Pesquisa - CAPPesq, do HC-FMUSP, protocolo de pesquisa 160/03.

1 Docente do Curso de Terapia Ocupacional da Faculdade de Medicina da Universidade de São Paulo (FMUSP).

2 Terapeuta Ocupacional do Curso de Terapia Ocupacional da Faculdade de Medicina da Universidade de São Paulo (FMUSP)..

3 Docente do Curso de Terapia Ocupacional da Universidade de Sorocaba (UNISO).

4 Docente do Curso de Terapia Ocupacional da Faculdade de Medicina da Universidade de São Paulo (FMUSP).

Endereço para correspondência: Curso de Terapia Ocupacional - FMUSP. Rua Cipotânea, 51. Cidade Universitária. C.E.P: 05360-160 Butantã. São Paulo. São Paulo. Brasil. E-mail: centroto@usp.br.
} 
LIMA, E. M. A., et al. Ação e criação na interface das artes. Rev. Ter. Ocup. Univ. São Paulo, v. 20, n. 3, p. 143-148, set./dez. 2009.

\section{Construindo uma nova perspectiva de atenção em Terapia Ocupacional}

partir de 1980 , observa-se na sociedade
brasileira dois movimentos voltados para a
melhoria da atenção à saúde que fortaleceram ações interdisciplinares e produziram novos sentidos nas práticas da terapia ocupacional. O primeiro refere-se à organização e luta das pessoas com deficiências por direitos às mesmas oportunidades sociais que a de outros cidadãos, pela melhoria das condições de vida e de seu entorno sócio-cultural. Este movimento influenciou a atitude de profissionais e da população em geral e introduziu novos conceitos e abordagens técnicas para o enfrentamento daquilo que nos campos da saúde e da cultura limitavam o acesso de deficientes aos bens culturais e sociais (ONU, 1996; SARACENO, 1999).

No mesmo período, o processo da Reforma Psiquiátrica brasileira introduzia experiências teóricas e práticas singulares para lidar com a complexidade das demandas no âmbito da saúde mental, contemplando ações realizadas para a desinstitucionalização dos pacientes psiquiátricos, visando a transformação concreta de suas vidas, a construção de seus direitos civis e de sua participação social (NICÁCIO, 1994).

No que concerne às atividades empregadas em terapia ocupacional, estes fatores dispararam a necessidade de produção técnica e científica voltada a essas populações, construindo propostas que buscassem, entre outras ações, garantir e assegurar oportunidades do uso de seus potenciais criativos, artísticos e intelectuais e o acesso a eventos e serviços culturais (ONU, 1996).

Observa-se também, nas intervenções de terapia ocupacional que se constituem na interface Arte-Saúde, a influência de uma nova noção de reabilitação baseada em ações no território que têm como sentido principal a construção dos direitos substanciais (afetivos, relacionais, materiais, habitacionais, produtivos e culturais) dos pacientes e um interesse em pesquisar as transformações ocorridas nas dinâmicas sociais, culturais e econômicas de populações em situação de vulnerabilidade e risco social (SARACENO, 1999; CASTRO, 2001; CASTRO, et al., 2003).

Assim, nos atendimentos realizados no âmbito da terapia ocupacional brasileira, identifica-se a necessidade de propostas que recuperem à vida sua dimensão criativa e proponham sua re-conexão com ritmos que favoreçam a maior integração pessoal e ambiental. Em decorrência destes fatores, há uma forte presença de atividades artísticas, plásticas e corporais nos campos da Terapia Ocupacional, nas ações de referência para a construção da Reabilitação e da Saúde. Estas atividades participam do conjunto de estratégias voltadas à construção de projetos de vida, da invenção de outras formas de participação social, de promoção de espaços de troca subjetiva e experimentação de modos inusitados de produção de valor pela população atendida (CASTRO, 2000; LIMA, 2003, 2005; INFORSATO, 2005).

\section{Laboratório de Estudos e Pesquisa Arte e Corpo em Terapia Ocupacional: pesquisa, formação e atenção à saúde.}

Em 1996, terapeutas ocupacionais, que anteriormente haviam participado de diferentes experiências profissionais relacionadas de modos distintos aos movimentos acima citados, criaram o Laboratório de Estudos e Pesquisa Arte e Corpo em Terapia Ocupacional no Curso de Terapia Ocupacional do Departamento de Fisioterapia, Fonoaudiologia e Terapia Ocupacional da Faculdade de Medicina da Universidade de São Paulo. Credenciado como Grupo de Pesquisa do Conselho Nacional de Pesquisa (CNPq), o Laboratório tem uma equipe constituída por docentes e terapeutas ocupacionais, com especializações e pós-graduações em campos interdisciplinares, que compõem o trabalho conjunto com estagiários de Graduação em Terapia Ocupacional, bolsistas de Programas internos da Universidade de São Paulo e de Agências Públicas de Fomento à Pesquisa (FAPESP e CNPq).

A atuação deste grupo vem produzindo metodologias de trabalho na interface das Artes e da Saúde, que estão sendo estudadas e pesquisadas, incrementando o conjunto de conhecimentos e de tecnologias neste campo e provocando mudanças nos paradigmas das ações em saúde, em educação e na produção artístico-cultural, potencializando a formação de alunos na graduação em Terapia Ocupacional e de outros profissionais das Artes, da Saúde e da Educação.

Trata-se de um trabalho que considera as situações limites vividas por sujeitos e populações que, mesmo no enfrentamento de estados clínicos e/ou de desvantagem social, não deixam de encontrar um fio que articula fragmentos de suas histórias a momentos criativos que dão origem a produções artísticas e imprimem transformações fundamentais a suas vidas. Desenhos, pinturas, modelagens, colagens, músicas, poesias, textos, narrativas, construções inusitadas, danças, performances, 
entre outras manifestações artísticas presentes na produção e na vida destes sujeitos e grupos singulares desencadeiam um movimento de encantamento e reflexão sobre o fundamental trabalho cotidiano de atender estas pessoas em terapia ocupacional. O olhar atento e o cuidado destes profissionais com as atividades realizadas também auxiliam no processo de inclusão sociocultural destas populações (CASTRO, 2001).

No cotidiano das práticas desenvolvidas enfrenta-se o desafio da construção de um conhecimento crítico e inovador capaz de articular múltiplas ações que situem a clínica da terapia ocupacional para além da fragmentação do saber, tão freqüente na área da saúde. A interdisciplinaridade é um pressuposto contemporâneo na consolidação desta área, e exige estudos que integrem outros campos do conhecimento - biológicos, psicológicos, antropológicos e sociais, exercício que Edgard Morin nomeia como um trabalho biopsicoantropossocial. Abrangência que para ser construída necessita de um trabalho por etapas aproximativas, configurando uma rede interligada de conceitos, onde não há uma hierarquia, mas o estudo de conceitos mutuamente consistentes, permitindo-nos abordar os problemas de forma a favorecer avanços e as inventividades necessárias. Este processo exige a presença de diversas pessoas que coletivamente estudem esta forma de abordagem para construção do conhecimento científico contemporâneo (MORIN apud CARVALHO, 1992).

Para tanto, o Laboratório foi estabelecendo parcerias com experiências e projetos que se constituem na interface da Arte e da Saúde, o que permitiu ampliar o campo assistencial e o número de pessoas beneficiadas com práticas nesta fronteira. Os projetos e instituições parceiros, ao longo do tempo, foram: o Museu de Arte Contemporânea da USP; os projetos de arte-educação da Associação Morungaba; a Escola de Música Sônia Silva; a Companhia Teatral Ueinzz; a Companhia de Dança Ingoma; as oficinas artísticas da Associação Brasileira de Assistência ao Deficiente Visual Laramara; Coral Cênico Cidadãos Cantantes; Atelieur Bricoleur; Centro de Convivência e Cooperativa Parque da Previdência; o Centro de Atenção Psicossocial - Lapa e o Centro de Cultura Popular Consolação. São diversos equipamentos de importância social e cultural que imprimem um caráter de rede às ações desenvolvidas pelo Laboratório e ampliam a contribuição da Terapia Ocupacional a propostas com características e interesses compartilhados, que operam como experiências singulares de transformação social.

Com a aproximação aos campos das artes e da educação, encontra-se na constituição do Laboratório de
Estudos e Pesquisa Arte e Corpo em Terapia Ocupacional uma proposição de trabalho que colabora para a estruturação e o fortalecimento da Terapia Ocupacional brasileira, através de uma multiplicidade de estratégias voltadas para a construção de respostas às complexas demandas da população atendida, que é afetada de forma cada vez mais expressiva pelas questões sociopolíticas do país. Estas estratégias proporcionam à profissão uma experiência articulada de ensino, pesquisa e extensão universitária, que se coletiviza e cria condições para o desenvolvimento de um conhecimento local e uma inovação das ações no âmbito das universidades brasileiras.

\section{O Programa Permanente Composições Artísticas e Terapia Ocupacional - o PACTO}

Entre as ações desenvolvidas pelo Laboratório há o PACTO - Programa Permanente Composições Artísticas e Terapia Ocupacional. Trata-se de um programa didáticoassistencial que nos permite atuar junto à população num processo empírico para a construção de metodologias de intervenção em terapia ocupacional, com referências básicas nos movimentos contemporâneos das Artes, da Reabilitação Psicossocial e da atenção às populações em desvantagem social.

O PACTO oferece atendimento vinculado ao Sistema Único de Saúde, de acordo com seus princípios e diretrizes. Atende a crianças, adolescentes, adultos e idosos que enfrentam problemáticas específicas - deficiências físicas, mentais ou sensoriais, desordens funcionais, transtornos clínicos, transtornos mentais e/ou psicológicos, ou situações de risco social -, e que apresentam dificuldades na realização de tarefas e atividades em seu cotidiano, enfrentando barreiras para a participação na vida sociocultural (BRASIL, 1990).

A realização deste projeto tem possibilitado a compreensão da importância de propostas contemporâneas que se situam na interface da Arte e da Saúde para populações expropriadas de suas redes de vida, pois seu desenvolvimento apresenta aberturas no processo de produção de saúde que pressupõe troca de saberes e diálogos que muitas vezes ultrapassam as fronteiras das práticas tradicionais em saúde (FOLDER, 1999 ; CANGUÇU et al., 2000).

\section{Proposta metodológica}

Pouco a pouco, transita-se por territórios de diferentes disciplinas e são inventados novos modos de compor com 
LIMA, E. M. A., et al. Ação e criação na interface das artes. Rev. Ter. Ocup. Univ. São Paulo, v. 20, n. 3, p. 143-148, set./dez. 2009.

elas ou a partir delas, seja por parceria, interferência, contaminação ou desvio. Nessas aproximações são criadas e desenvolvidas práticas clínicas, educacionais, sociais e culturais, que buscam atingir o objetivo principal de nossa proposta que é garantir a participação da população atendida em terapia ocupacional em espaços socioculturais da coletividade urbana.

O PACTO se propõe a acompanhar grupos no desenvolvimento de projetos em artes plásticas e artes do corpo e inclui em sua metodologia de trabalho: o fazer artístico, através da instrumentalização técnica em ateliês de experimentação plástica e corporal; a atualização cultural, por meio de passeios e visitas a eventos da cidade; e a divulgação das produções realizadas, através de exposições e feiras, abrindo assim, mais uma forma de engendrar a participação destas pessoas e seus trabalhos no circuito sociocultural (PILLAR; VIEIRA, 1992; BARBOSA, 1998).

A relação com o universo das produções culturais possibilita o contato com novas formas de sensibilidade disponíveis ao coletivo, que podem orientar cada um em sua própria experimentação no enfrentamento dos desafios que o mundo contemporâneo coloca.

As atividades artísticas desenvolvidas no PACTO são compreendidas como construções capazes de acolher e dar forma a vivências singulares que extravasam e tensionam os limites hegemônicos de entendimento e de elaboração na linguagem verbal, possibilitando outras formas de expressão. Por isso, estas manifestações, circunscritas ao âmbito das atividades e produções humanas, embora oriundas do campo da Saúde e das práticas clínicas, tocam as fronteiras das Artes e se configuram como fato cultural. Busca-se ampliar o universo de relações dos sujeitos atendidos, enriquecer o cotidiano, redefinir papéis sociais promovendo a constituição e convivência grupal e a circulação social. Para que isto ocorra, nossas ações práticas se dão também no território da cidade, favorecendo novas maneiras de estar e de existir nos processos sociais com as deficiências, doenças ou desvantagens sociais (CASTRO, 2000; LIMA, 2003, 2005; INFORSATO, 2005).

\section{As pessoas envolvidas e o atendimento realizado}

Os grupos atendidos no PACTO apresentam constituições heterogêneas, formadas, não a partir de uma marca diagnóstica ou social, mas de acordo com interesses e necessidades singulares das pessoas e relacionadas ao processo de trabalho grupal em desenvolvimento. A intenção é engendrar com os participantes a potência de uma composição heterogênea que evita anular ou achatar as diferenças, direcionando-as para que elas sejam motores de encontro e pertença social.

A capacidade de atendimento faz com que se priorize o atendimento de pessoas de baixa renda, considerando entre outras coisas, a dificuldade de acesso dessas pessoas a serviços de atenção à saúde. Assim, a população atendida pelo projeto caracteriza-se por um perfil sócioeconômico, com carência de diversas ordens: problemas de moradia, de transporte, dificuldade de acesso à escola, ao mercado de trabalho e às redes de convivência em geral. Os participantes chegam ao projeto encaminhados por equipamentos de saúde e de cultura, por profissionais de diversas áreas, ou por busca espontânea. A procura pelo programa se dá pela necessidade de atendimento em terapia ocupacional; pela busca de lugares de convivência; pela tentativa de encontrar espaços de aprofundamento técnico e de experimentação em linguagens plásticas e corporais.

O processo de atendimento do PACTO se inicia por uma entrevista inicial, na qual se explora os aspectos da história de vida e do cotidiano, as experiências anteriores com atividades, bem como a história clínica e as redes de sociabilidade que a pessoa possui e sua demanda atual para este programa. Quando a demanda de atendimento não pode ser respondida pelo projeto, a equipe busca encaminhar os sujeitos segundo as necessidades observadas e apresentadas. Já localizada a pertinência ao projeto, a pessoa é convidada a conhecer e participar de um dos grupos do PACTO e, se necessário, são organizados atendimentos individuais que buscam prepará-la para a participação nestes grupos.

As ações desenvolvidas nesses grupos criam fendas no tecido social e buscam produzir novas linhas de conexão para o exercício da vida. O programa atua numa perspectiva global em relação às várias dimensões da vida dos sujeitos, e a saúde passa a ser entendida como produção, conexão e re-conexão às redes de vida, o que implica uma multiplicidade de intervenções e ações que vão além da reparação do dano ou do genérico bem-estar físico-psíquico-social.

Além dos grupos de atividades artísticas e culturais, construiu-se a Rede de Sustentação, com acompanhamento terapêutico, atendimentos individuais e familiares, cujo objetivo é viabilizar e sustentar aos participantes, com demandas clínicas específicas, o acolhimento de suas singularidades nos grupos e nas atividades do PACTO. É também objetivo do trabalho na Rede de Sustentação acompanhar os participantes na inserção em projetos 
LIMA, E. M. A. et al. Ação e criação na interface das artes. Rev. Ter. Ocup. Univ. São Paulo, v. 20, n. 3, p. 143-148, set./dez. 2009.

artísticos e culturais oferecidos pela comunidade, tais como, Museus, Oficinas e Escolas de Arte. Desta forma, o PACTO visa constituir-se em um lugar intermediário entre os espaços clínicos e o campo sociocultural mais amplo, no qual os usuários possam encontrar uma rede de convivência e formação em arte (CASTRO et al., 2005).

Como um projeto orgânico e flexível que vai ganhando formas a partir das necessidades dos sujeitos atendidos, esta proposta de atenção foi se desenhando do seguinte modo: entrevistas iniciais, triagem e avaliações terapêuticas ocupacionais; atendimentos grupais em atividades artísticas - Ateliês Experimentais, Pacto Crianças, Pacto Trabalho, Pacto Exposição, Pacto Passeio/ Atividades Culturais; atendimentos individuais na Rede de Sustentação (CASTRO et al., 2005).

Para atender as problemáticas complexas e graves de muitos dos usuários do programa, a eles é oferecida a oportunidade de participar de mais de uma das modalidades de atendimento, visando um atendimento clínico de maior intensidade. Um mesmo usuário pode, por exemplo, ser atendido individualmente, participar de um grupo semanal do PACTO e ainda participar do PACTO passeio/ atividades culturais.

De forma bastante artesanal, quando necessário, projetos de vida são elaborados conjuntamente com cada usuário ou com suas famílias, com investimento na construção dos direitos e da cidadania, na atenção aos trajetos da afetividade e reconstrução de histórias de vida. Os terapeutas ocupacionais do programa têm a função de interlocutores e mediadores entre os usuários e os espaços sociais, criando as condições necessárias para, parafraseando Safra (2004), "o acontecer humano na época atual".

Neste sentido, além da atividade assistencial, o Programa tem também o objetivo de formar profissionais para atuar no trabalho e ensino dos temas das artes e do corpo, no acompanhamento de pessoas e na mediação e interlocução dessas com o corpo social, o que implica uma formação múltipla e interdisciplinar, composta por conhecimentos do campo das artes, da terapia ocupacional e da educação, além de uma constante invenção de estratégias para a construção da participação sociocultural.

Disto decorre que, além dos atendimentos aos sujeitos, o Laboratório realize atividades diversas de acompanhamento de estudantes de graduação e bolsistas - através de supervisões, reuniões, grupos de estudos - e de divulgação dos trabalhos realizados para a comunidade científica e para outros grupos sintonizados com a importância desta experiência desenvolvida na Universidade de São Paulo.

\section{Perspectivas}

Ao realizar um trabalho processual, de construção contínua, os profissionais do Laboratório de Estudos e Pesquisa Arte e Corpo em Terapia Ocupacional têm provocado tensionamentos e promovido aberturas nos espaços artísticos e culturais do próprio território para que a população atendida nas redes de saúde sejam também neles recebida. Instauram-se possibilidades de enfrentamento dos processos de homogeneização das diferenças, agindo sobre as tendências históricas e culturais de institucionalização e desvalorização que acompanham e produzem marcas, enfraquecendo as vidas dos sujeitos. O trabalho constituído na interface entre a terapia ocupacional e as artes, gera potência ao deslocar a clínica para o campo da invenção e produzir novos agenciamentos para os técnicos e para os usuários. A aposta é que novas sociabilidades e novas formas de resistências aos processos de exclusão possam ser engendradas a partir desta proposta.

No âmbito da Graduação e das atividades científicas, nossos objetivos são: estruturar o Laboratório de Estudos e Pesquisa Arte e Corpo em Terapia Ocupacional para o desenvolvimento e a continuidade de pesquisas e da produção do conhecimento; dar maior consistência ao programa didático-assistencial aprofundando estudos teóricos e reflexões das práticas realizadas; organizar e fortalecer as ações práticas desenvolvidas; e divulgar as produções nos meios científicos e culturais para que as transformações do trabalho realizado possam multiplicarse nos campo das Artes, da Saúde e da Educação.

Como perspectivas para este trabalho pode-se apontar: o investimento na formação de terapeutas ocupacionais especializados no atendimento na interface arte-saúde; a ampliação e estruturação do conhecimento da equipe profissional para as ações nesta interface; o desenvolvimento de convênios, parcerias, cooperações que garantam o acesso aos serviços oferecidos pela comunidade; a ampliação da captação de recursos financeiros para garantir a sustentabilidade e o crescimento deste Programa.

Trata-se de um compromisso coletivo com a vida, em sua potência de multiplicidade e variação, com profissionais de saúde, educadores, artistas, estudantes e usuários de nossos serviços. 
LIMA, E. M. A., et al. Ação e criação na interface das artes. Rev. Ter. Ocup. Univ. São Paulo, v. 20, n. 3, p. 143-148, set./dez. 2009.

LIMA, E. M. A.; INFORSATO, E. A.; LIMA, L. J. C. de; CASTRO, E. D. de. Action and creation at the arts and healthcare interface. Rev. Ter. Ocup. Univ. São Paulo, v. 20, n. 3, p. 143-148, set./dez. 2009.

\begin{abstract}
This article presents the experience of constituting and establishing the Laboratory of Study and Research in Arts, Body and Occupational Therapy and the Artistic Composition and Occupational Therapy Permanent Program of USP, Brazil. To outline a scenario of teaching and researching activities and those involving the community composing a new field of occupational therapy practices focused on the complex demands of the population assisted in this area and on increasing their socio-cultural participation. This group have been done qualitative research conducted through an action-research methodology to build up local awareness of occupational therapy due to the importance of creative actions and clinical and cultural-artistic references. The actions taken have broadened the access of the population assisted to artistic activities and cultural experiences standing for strategies to build life projects, ways of participating in community life, networking and making subjective exchanges, which have resulted in unexpected production of social value.
\end{abstract}

KEY WORDS: Occupational therapy/trends. Art therapy/trends. Social investiment projects.

\title{
REFERÊNCIAS
}

BARBOSA, A. M. Tópicos utópicos. Belo Horizonte: C/Arte, 1998.

BRASIL. Ministério da Saúde. Áreas temáticas: SUS. Brasília: Ministério da Saúde, 1990. Disponível em: <http://portal.saude. gov.br/portal/arquivos/pdf/sus_3edicao_completo.pdf.> Acesso em: 09 set. 2009.

CANGUÇU, D. F.; CASTRO, E. D.; COSTA, A. L. B.; INFORSATO, E. A.; LIMA, E. A.; LIMA, L. J. C. Programa Permanente de Composições Artísticas e Terapia Ocupacional (PACTO): uma proposta de Atenção na Interface Arte-Saúde. Rev. Ter. Ocup. Univ. São Paulo, v. 11, n. 2/3, p. 45-55, 2000.

CARVAlHO, E. de A. A declaração de Veneza e o desafio transdisciplinar. Rev. Margem. v. 1, p. 91-103, 1992.

CASTRO, E. D. Atividades artísticas e Terapia Ocupacional: construção de linguagens e inclusão social. 2001. 326fls. Tese (Doutorado em Ciências da Comunicação). Escola de Comunicação e Artes da Universidade de São Paulo, São Paulo, 2001.

CASTRO, E. D. Arte, corpo e terapia ocupacional: aproximações, intersecções e desdobramentos Rev. Ter. Ocup. Univ. São Paulo, v. 11, n. 1, p. $7-12,2000$.

CASTRO, E. D.; INFORSATO, E. A.; LIMA, E. A.; LIMA, L. J. C. Projeto Didático-Assistencial Programa Permanente Composições Artísticas e Terapia Ocupacional, encaminhado a ABADHS, junho 2003.

CASTRO, E. D.; SAITO, C. M.; FONSECA, F. V. D. Projeto Corpo e Arte: articulando ações em Terapia Ocupacional. Relatório Científico Final. São Paulo: FAPESP, 2005.
Folder do Laboratório de Estudo e Pesquisa "Arte e Corpo em Terapia Ocupacional”. São Paulo CDPTO-USP, 1999.

INFORSATO, E. Clínica Barroca: exercícios de simpatia e feitiçaria. 2005. 169fls. Dissertação (Mestrado). Pontifícia Universidade Católica de São Paulo. São Paulo, 2005.

LIMA, E. M. F. A. Das obras aos procedimentos: ressonâncias entre os campos da Terapia Ocupacional e das Artes. 2003. 344 fls. Tese (Doutorado). Pontifícia Universidade Católica de São Paulo. São Paulo, 2003.

LIMA, L. J. C. Viver e envelhecer com qualidade: interfaces da Terapia Ocupacional, atividades artísticas e gerontologia. 2005. $210 \mathrm{fls}$. Dissertação (Mestrado). Pontifícia Universidade Católica de São Paulo. São Paulo, 2005.

NICÁCIO, M. F. O processo de transformação em saúde mental em Santos:desconstrução de saberes, instituições e cultura. 1994. 193 fls. Dissertação (Mestrado). Pontifícia Universidade Católica de São Paulo. São Paulo, 1994.

ONU. Normas sobre a equiparação de oportunidade para pessoas com deficiencia. São Paulo: APADE 7; CVI-NA, 1996.

PILLAR, A.; VIEIRA, D. O vídeo e a metodologia triangular no ensino da arte. Porto Alegre: UFRS/Fundação FOCHPE,1992.

SAFRA, G. A po-ética da clínica contemporânea. São Paulo: Idéias e Letras, 2004.

SARACENO, B. Libertando identidades: da reabilitação psicossocial à cidadania possível. Rio de Janeiro: Instituto Franco Basaglia-Te Corá, 1999. 